\title{
Apoptosis-Independent Reduction of Programmed Death Ligand-1 Levels by Boningmycin Through AMPK-Mediated Endoplasmic Reticulum- Associated Protein Degradation in Human Tumor Cells
}

Juan Zhang

Chinese Academy of Medical Sciences \& Peking Union Medical College Institute of Medicinal Biotechnology

Jin-Cai Wang

Chinese Academy of Medical Sciences \& Peking Union Medical College Institute of Medicinal Biotechnology

\section{Yue Shang}

Chinese Academy of Medical Sciences \& Peking Union Medical College Institute of Medicinal Biotechnology

\section{Yang Chen}

Chinese Academy of Medical Sciences \& Peking Union Medical College Institute of Medicinal Biotechnology

\section{Shu-Zhen Chen}

Chinese Academy of Medical Sciences \& Peking Union Medical College Institute of Medicinal Biotechnology

Qi-Yang He ( $\nabla$ heqiyang@imb.pumc.edu.cn )

Chinese Academy of Medical Sciences \& Peking Union Medical College Institute of Medicinal Biotechnology https://orcid.org/0000-0003-3694-6036

\section{Research Article}

Keywords: boningmycin, PD-L1, apoptosis, AMP-activated protein kinase, endoplasmic reticulumassociated degradation pathway

Posted Date: October 29th, 2021

DOI: https://doi.org/10.21203/rs.3.rs-1016961/v1 
License: (c) (i) This work is licensed under a Creative Commons Attribution 4.0 International License. Read Full License 


\section{Abstract}

Boningmycin (BON), a new member of the bleomycin family, exhibits highly potent activity against tumor cells in vitro and in vivo. It remains unclear if BON can affect the protein levels of programmed death ligand-1 (PD-L1) in a manner similar to that of other antitumor agents. Potent inhibition of cell survival by BON was observed in non-small-cell lung cancer $\mathrm{NCl}-\mathrm{H} 460$ cells and sarcoma HT1080 cells. Apoptosisindependent reduction of PD-L1 was observed after exposure to BON. Furthermore, BON-treatment increased AMP-activated protein kinase phosphorylation, however, this increase was suppressed by treatment with specific inhibitor (compound C) or RNAi-mediated knockdown of AMPKa. BON-induced PD-L1 reduction is mediated by the endoplasmic reticulum-associated degradation pathway. Its mode of action is similar to that of metformin on the PD-L1 protein. In conclusion, it is firstly reported that BON can decrease PD-L1 protein levels through the AMPK activated endoplasmic reticulum- associated degradation pathway.

\section{Background}

Boningmycin (BON) is a new member of the bleomycin (BLM) family that exerts highly potent action on cancer cells in vitro and in vivo [1]. Its action can be affected by bleomycin hydrolase (BLH) and NF-E2related factor 2 according to our previous studies [2,3]. BLM is currently used as a first-line treatment regimen for certain types of cancers, including testicular cancer and lymphoma [4,5]. Accumulating evidence indicates that the mechanism of BLM in regard to DNA breakage requires cellular activation of BLM binding with reduced transition metal iron or copper ions [6]. Therefore, an urgent need exists to identify new molecular targets associated with the action of BON.

Immune checkpoint inhibitors, such as programmed death-1 (PD-1) or its ligand-1 (PD-L1) antibody, are widely used to treat various types of cancer [7]. These drugs have been shown to be more effective in patients possessing PD-L1-expressing cancer cells [8]. Moreover, PD-L1 overexpression plays an important role in cancer cells, such as promoting tumor growth and being associated with poor prognosis $[9,10]$. PD-L1 can compete with RNA exosomes in response to DNA damage [11]. Increased PD-L1 expression confers resistance to gefitinib and erlotinib in non-small cell lung cancer [12]. Therefore, PD-L1 in cancer cells may present a potential drug target for improving therapeutic efficacy. A number of drugs including antitumor agents have been reported to regulate PD-L1 expression [13]. The tyrosine protein kinase inhibitors osimertinib and gefitinib reduce PD-L1 levels in non-small cell lung cancer [14]. Metformin (MET), a first-line drug for the treatment of type 2 diabetes, is also effective in cancer therapy [15]. This drug causes the degradation of PD-L1 through the process of endoplasmic reticulumassociated degradation (ERAD) after activation of AMP-activated protein kinase (AMPK) [16].

Apoptosis, one mode of cell death, plays an important role in mediating antitumor mechanism of antitumor agents [17]. Many proteins are degraded in the progression of apoptosis, such as PARP-1, BLH [18]. In the present study, we explored whether BON affects PD-L1 protein levels in apoptosis-dependent manner in tumor cells. 


\section{Materials And Methods}

\section{Drugs and chemicals}

BON was kindly supplied by Professor Yun-ying Xie at our institute. Other chemicals were purchased from Selleck Chemicals (Houston, TX, USA) or Sigma-Aldrich (St. Louis, MO, USA) unless otherwise specified.

\section{Cell lines and cell culture}

All cell lines were acquired from the Cell Bank of the Type Culture Collection of the Chinese Academy of Sciences. The cells were cultured in RPMI-1640 (NCl-H460 cells), F12 (A549 cells), MEM (HT-1080 cells) or DMEM (MDA-MB-231 cells) medium (HyClone, UT, USA), and that was supplemented with $10 \%$ fetal bovine serum (Gibco, NY, USA) was supplemented. All cells were cultured in a humidified atmosphere at $37^{\circ} \mathrm{C}$ with $5 \% \mathrm{CO}_{2}$.

\section{Western blot assay}

Western blot assay has been described in detail previously [19]. Antibodies against PD-L1 (\#13684), PARP-1 (\#9542), cleaved caspase-3 (\#9661), p-AMPKa (\#2535), AMPKa (\#2532), LC3B (\#2775) and HRD1 (\#14773) were purchased from Cell Signaling Technology (Boston, MA, USA). The $\beta$-actin (sc47778) antibody was obtained from Santa Cruz Biotechnology (Santa Cruz, CA, USA). The antibody dilution ratios for $\beta$-actin and cleaved caspase-3 were 1:100,000 and 1:500, and those for the others were all 1:1000.

\section{CCK-8 assay}

The Cell Counting kit-8 (CCK-8) assay was performed according to the method published in our previous paper [19]. CCK-8 was obtained from Bimake (Houston, TX, USA). The operation steps and calculation formula for cell survival rates have been described previously.

\section{Mice xenografts and drug administration}

Female BALB/c nude mice weighing 18-22 g were purchased from SiPeiFu Beijing Biotechnology Co., Ltd (Beijing, China). $\mathrm{NCl}-\mathrm{H} 460$ cells were used for the establishment of a xenograft model. Tumor-bearing mice were randomly divided into three groups that included the vehicle group, BON $1 \mathrm{mg} / \mathrm{kg}$ group, BON 9 $\mathrm{mg} / \mathrm{kg}$ group. The mice were administrated with BON (i.p.) every two days. The body weights and tumor volumes were measured. After seven drug administrations, the mice were sacrificed and the tumor masses were separated. The care and sacrifice of nude mice were performed according to the protocols approved by the Animal Care and Use Committee of the Institute of Medicinal Biotechnology.

\section{Detection of apoptotic cells by Annexin V/PI staining}

The collected cells were stained with annexin $\mathrm{V}$ and $\mathrm{PI}$ according to the manufacturer's the instructions. The fluorescence intensities were measured using a flow cytometer (BD FACSCalibur, BD Biosciences). 
CellQuest Pro software version 5.1 was used for data analysis.

\section{RNA interference}

The siRNAs targeting PD-L1, AMPKa1, AMPKa2 and HRD1 were synthesized by Guangzhou RiboBio Co., Ltd (Guangzhou, China). The detailed transfection steps and conditions have been described previously [19]. The sequences of specific siRNAs are as follows:

AMPKa1\#1: 5'-GCAAAGTGAAGGTTGGCAA-3';

AMPKa1\#2: 5'- CCAGGATCCTTTGGCAGTT-3';

AMPKa2\#1: 5'-CTGAAGTTTACCGAGCTA-3';

AMPKa2\#2: 5'-GCATATGGTTGTTCATCGA-3';

HRD1\#1: 5'-CATGTACACAGCCTTGTTG-3';

HRD1\#2: 5'- AAACGGTGAAGGCCAGACA -3'.

\section{Statistical analysis}

Data from three separate experiments are shown as mean \pm SD. Statistical analyses were performed using SPSS software version 19.0. Comparisons between two groups were conducted using Student's ttest, whereas the differences among more than two groups were compared by one way ANOVA. Statistical significance was indicated as $* P<0.05$, $* * P<0.01$ and $* * * P<0.001$.

\section{Results}

\section{Reduction of PD-L1 in the progression of BON-induced apoptosis}

Cell lines exhibiting high PD-L1 expression (Sup. Fig. 1a) were used for the present study. As shown in Fig. $1 \mathrm{a}$ and b, NCl-H460 and HT-1080 cells were sensitive to BON and BLM, while MDA-MB-231 cells exhibited severe drug resistance to these drugs. The inhibitory efficacy of BON is stronger than that of BLM.

Apoptotic cell rates were elevated according to Annexin V/PI staining assay after exposure to BON for 36 h (Fig. 1c). Similar changes occurred in response to the BLM (data not shown). The levels of PD-L1 protein in $\mathrm{NCl}-\mathrm{H} 460$ cells were markedly reduced after treatment with BON or BLM (Fig. 1d). The activation of apoptotic pathway was also detected during the same time period. The cleavages of PARP-1 and caspase-3 were clearly observed with increasing BON concentrations (Fig. $1 \mathrm{~d}$ to g). A xenograft model of $\mathrm{NCl}-\mathrm{H} 460$ cells in nude mice was used to evaluate BON action in vivo (Fig. $1 \mathrm{~h}$ ). A reduction of PD-L1 protein levels in the BON $9 \mathrm{mg} / \mathrm{kg}$ group was detected in the tumor masses from $\mathrm{NCl}-\mathrm{H} 460$ cell xenografts (Fig. $1 \mathrm{i}$ and k). 
We also observed that the PD-L1 protein level decreased significantly in the HT-1080 cells after exposure to BON for $48 \mathrm{~h}$ (Sup. Fig. 1b). However, the cleavage of PARP-1 was not clearly detected. Compared to levels in the control group, PD-L1 protein levels decreased markedly in the BLM-treated groups. In contrast, different results were obtained in MDA-MB-231 cell line. The protein levels of PD-L1 were slightly elevated after treatment with BON for $48 \mathrm{~h}$ (Sup. Fig. 1d). Therefore, the MDA-MB-231 cell line was not used in the subsequent experiments.

\section{Apoptosis-independent reduction of PD-L1 protein levels by BON}

To rule out the apoptotic pathway in BON-induced PD-L1 protein reduction, the pan-caspase inhibitor zVAD was used for pretreatment of $\mathrm{NCl}-\mathrm{H} 460$ cells. The cleavage of PARP-1 protein was significantly inhibited by zVAD pretreatment, and the PD-L1 protein level was decreased during incubation with $5 \mu \mathrm{M}$ BON (Fig. 2a). These results were further confirmed through the using BON treatment over short time periods as activation of the apoptotic pathway occurred over long time periods in our previous studies [1, 3]. The results revealed that PD-L1 protein levels markedly decreased after incubation with BON for $8 \mathrm{~h}$, and the cleavage of the PARP-1 protein was not detected (Fig. 2b). A similar trend was observed in the BLM treated group. The PD-L1 protein level gradually decreased after treatment with $20 \mu \mathrm{M}$ BON or BLM for $8 \mathrm{~h}$ (Sup. Fig. $2 \mathrm{~b}$ ). This phenomenon was observed in HT-1080 cells after treatment with BON or BLM for $8 \mathrm{~h}$ (Sup. Fig. 2c). These results revealed that the apoptotic pathway is not involved in BON-induced reduction of PD-L1 protein levels.

PD-L1 is a transmembrane protein that can be abnormally expressed on the surface of cancer cells, ultimately leading to immune escape [7]. Therefore, we determined if cell surface PD-L1 protein level were reduced after incubation with BON. We observed no obvious difference in PD-L1 protein levels in live cells when comparing the BON-treated group and the control group (Sup. Fig. 2d).

To clarify the specificity of BON-induced PD-L1 protein reduction, the inducible PD-L1 protein expression was investigated. IFN- $y$ has been reported to significantly increase expression levels of PD-L1 in A549 cells [20]. PD-L1 protein levels were markedly elevated after $12 \mathrm{~h}$ of exposure to various concentrations of IFN-y. The inducible PD-L1 protein levels were reduced after exposure to $20 \mu \mathrm{M} \mathrm{BON}$ for $8 \mathrm{~h}$ (Fig. $2 \mathrm{~d}$ ). These data demonstrate that BON-induced reduction of PD-L1 protein levels is relatively specific.

\section{Involvement of AMPK activation in BON-induced PD-L1 protein reduction}

As BLM and BON are DNA-damaging agents, they appear to have no effect on protein degradation [6]. The PD-L1 mRNA levels were not affected by BON treatment according to a quantitative real-time PCR assay (data not shown), suggesting that this phenomenon occurs at the protein level. Therefore, we hypothesized that the mode of BON action is similar to that of metformin in regard to the PD-L1 protein. As shown in Fig. 3a, the phosphorylation levels of AMPKa were clearly elevated after exposure to increased concentrations of BON for $8 \mathrm{~h}$, suggesting that BON treatment can activate AMPK. Furthermore, compound C (Com C), a specific AMPK inhibitor, inhibited the phosphorylation of the AMPKa protein and reduced the PD-L1 protein levels after exposure to BON or MET (Fig. 3b). Finally, these phenomena were 
further confirmed through the knockdown of AMPKa using RNA interference. As AMPKa is composed of AMPKa1 protein and AMPKa2 proteins [21], the effective reduction of AMPKa was required for cotransfection with AMPKa1-siRNA and AMPKa2-siRNA. As shown in Fig. 3c and e, AMPKa protein levels were significantly reduced after co-transfection, whereas the PD-L1 protein levels did not decrease after exposure to BON or MET. These findings demonstrate that AMPK activation is necessary for BON-induced PD-L1 protein reduction.

\section{An ERAD-related pathway mediates BON-induced PD-L1 protein reduction}

We next focused on clarifying the protein degradation pathway underlying BON-induced PD-L1 protein reduction. The reduction of PD-L1 protein caused by BON treatment was suppressed when $\mathrm{NCl}-\mathrm{H} 460$ cells were pretreated with the proteasome inhibitor MG-132 (Fig. 4a). However, hydroxychloroquine, an inhibitor of the autophagy- lysosomal pathway, did not inhibit the decrease of PD-L1 protein levels caused by BON treatment (data not shown).

It has been reported that degradation of PD-L1 protein by MET occurs through the ERAD-related pathway after AMPK activation [16]. Eeyarestatin I (Eer I), a specific inhibitor of the ERAD pathway, inhibited the reduction of PD-L1 protein caused by BON or MET treatments (Fig 4b). We then silenced the hrd1, an important component of the ERAD pathway. As shown in Fig. 4c and d, HRD1 protein levels were obviously decreased, and the PD-L1 protein levels were no longer reduced in the transfected cells exposed to BON or MET. These data illustrate that the reduction of PD-L1 protein levels caused by BON is ERADdependent, and this is similar to MET action.

\section{Discussion}

In the present study, the PD-L1 protein levels were significantly reduced by BON treatment through the AMPK-activated ERAD pathway in tumor cells. To the best of our knowledge, this is the first report demonstrating that bleomycin-related compounds can decrease PD-L1 protein levels. These findings will benefit the development of BON and serve to further demonstrate the molecular mechanism of BLMrelated compounds.

AMPK plays a critical role in cellular metabolism and energy balance. Numerous compounds from plants, including resveratrol and berberine, exert antitumor effects through activation of AMPK [21]. The findings that BON can activate AMPK is consistent with a previous report examining BLM action; however, it is not involved in potentiation of BLM action by vitamin $\mathrm{C}$ in $\mathrm{NCl}-460$ and $\mathrm{A} 549$ cells [22]. Suppression of mTOR activity during the DNA damage response is mediated by AMPK activation [23]. The main side effect of BLM is pulmonary fibrosis [6]. The main action of MET is through activation of AMPK [15]. MET can reverse BLM-induced lung fibrosis via AMPK activation [24]. However, we did not observe the synergistic actions of BON and MET in tumor cells (data not shown). Therefore, this combination treatment appears to trigger a different pathway between AMPK-mediated PD-L1 degradation and AMPK-suppressed lung fibrosis. 
Accumulating evidence indicates that BLM is a genotoxic agent that generates DNA double-strand breaks in a manner similar to that of radiation treatment [6]. In the present study, we demonstrated that BON and BLM can degrade PD-L1 protein via AMPK activation, and this broadens our understanding of BLMrelated compound actions on tumor cells. As iron chelator and vitamin $\mathrm{C}$ cannot affect BON-induced PDL1 protein reduction (data not shown), this action may not be involved the function of DNA damage after the entry of BON into cells.

The high sensitivity to $\mathrm{BON}$ in $\mathrm{NCl}-\mathrm{H} 460$ lung cancer cells may be low level of $\mathrm{BLH}$ as it has reported that there is low level of BLH in lung organ [25]. The drug resistance to BON in breast MDA-MB-231 cells may be result from high expression of BLH in this cell line [26]. Therefore, low level of BLH in lung organ is suitable for studying the action of BON on PD-L1 protein level as it rules out the interference of BLH with action of BON.

In summary, BON can reduce PD-L1 protein levels through degradation of the AMPK-activated ERAD pathway. This phenomenon occurs in apoptosis-independent manner. These findings will benefit the development of BON for use in cancer therapy and will aid in the elucidation of the molecular mechanism of BLM-related compounds.

\section{Declarations}

\section{Acknowledgments}

The work was supported by grants from National Natural Science Foundation of China (31471150)

Conpeting interest The authors declare that they have no competing interests.

Ethical approval Not applicable.

Consent for publication Not applicable

\section{References}

1. Gao N, Shang B, Zhang X, Shen C, Xu R, Xu H, et al. Potent antitumor actions of the new antibiotic boningmycin through induction of apoptosis and cellular senescence. Anticancer Drugs 2011; 22:166-75.

2. Chen $\mathrm{Y}$, Zhang $\mathrm{H}, \mathrm{He} \mathrm{Q}$. Involvement of bleomycin hydrolase and poly(ADP- ribose) polymerase-1 in Ubc9-mediated resistance to chemotherapy agents. Int J Oncol. 2017; 50: 223-31.

3. Zhang HX, Chen Y, Xu R, He QY. Nrf2 mediates the resistance of human A 549 and HepG2 cancer cells to boningmycin, a new antitumor antibiotic, in vitro through regulation of glutathione levels. Acta Pharmacol Sin. 2018; 39: 1661-9.

4. Hanna NH, Einhorn LH. Testicular cancer-discoveries and updates. N Engl J Med. 2014; 371: 20052016. 
5. Laddaga FE, Moschetta M, Perrone T, Perrini S, Colonna P, Ingravallo G, et al. Long-term hodgkin lymphoma survivors: a glimpse of what happens 10 years after treatment. Clin Lymphoma Myeloma Leuk. 2020; 20: e506-12.

6. Chen J, Stubbe J. Bleomycins: towards better therapeutics. Nat Rev Cancer. 2005; 5: $102-112$.

7. Galon J, Bruni D. Approaches to treat immune hot, altered and cold tumours with combination immunotherapies. Nat Rev Drug Discov. 2019; 18: 197-18.

8. Gettinger S, Horn L, Jackman D, Spigel D, Antonia S, Hellmann M,et al. Five-year follow-up of nivolumab in previously treated advanced non-small-cell lung cancer: results from the CA209-003 study. J Clin Oncol. 2018; 36: 1675-84.

9. Kleffel S, Posch C, Barthel SR, Mueller H, Schlapbach C, Guenova E, et al. Melanoma Cell-Intrinsic PD1 Receptor Functions Promote Tumor Growth. Cell 2015; 162: 1242-56.

10. Black M, Barsoum IB, Truesdell P, Cotechini T, Macdonald-Goodfellow SK, Petroff M, et al. Activation of the PD-1/PD-L1 immune checkpoint confers tumor cell chemoresistance associated with increased metastasis. Oncotarget 2016; 7: 10557-67.

11. Tu X, Qin B, Zhang Y, Zhang C, Kahila M, Nowsheen S, et al. PD-L1 (B7-H1) competes with the RNA exosome to regulate the DNA damage response and can be targeted to sensitize to radiation or chemotherapy. Mol Cell. 2019; 74: 1215-26.

12. Lin PL, Wu TC, Wu DW, Wang L, Chen CY, Lee H. An increase in BAG-1 by PD-L1 confers resistance to tyrosine kinase inhibitor in non-small cell lung cancer via persistent activation of ERK signalling. Eur J Cancer. 2017; 85: 95-105.

13. Prestipino A, Zeiser R. Clinical implications of tumor-intrinsic mechanisms regulating PD-L1. Sci Transl Med. 2019; 11: eaav4810.

14. Jiang XM, Xu YL, Huang MY, Zhang LL, Su MX, Chen X, Lu JJ. Osimertinib (AZD9291) decreases programmed death ligand-1 in EGFR-mutated non-small cell lung cancer cells. Acta Pharmacol Sin. 2017; 38: 1512-20.

15. Foretz M, Guigas B, Bertrand L, Pollak M, Viollet B. Metformin: from mechanisms of action to therapies. Cell Metab. 2014; 20: 953-66.

16. Cha JH, Yang WH, Xia W, Wei Y, Chan LC, Lim SO, et al. Metformin promotes antitumor immunity via endoplasmic-reticulum-associated degradation of PD-L1. Mol Cell. 2018; 71: 606-20.

17. Johnstone RW, Ruefli AA, Lowe SW. Apoptosis: a link between cancer genetics and chemotherapy. Cell. 2002; 108: 153-64.

18. Chen Y, Xu R, Chen J, Li X, He Q. Cleavage of bleomycin hydrolase by caspase-3 during apoptosis. Oncol Rep. 2013; 30: 939-44.

19. Zhang J, Chen Y, He Q. Distinct characteristics of dasatinib-induced pyroptosis in gasdermin Eexpressing human lung cancer A549 cells and neuroblastoma SH-SY5Y cells. Oncol Lett. 2020; 20: 145-54. 
20. Lee SJ, Jang BC, Lee SW, Yang YI, Suh SI, Park YM, et al. Interferon regulatory factor-1 is prerequisite to the constitutive expression and IFN-gamma-induced upregulation of B7-H1 (CD274). FEBS Lett. 2006; 580: 755-62.

21. Steinberg GR, Carling D. AMP-activated protein kinase: the current landscape for drug development. Nat Rev Drug Discov. 2019; 18: 527-51.

22. Rubis B, Luczak MW, Krawic C, Zhitkovich A. Vitamin C increases DNA breaks and suppresses DNA damage-independent activation of ATM by bleomycin. Free Radic Biol Med. 2019; 136: 12-21.

23. Budanov AV, Karin M. p53 target genes sestrin1 and sestrin2 connect genotoxic stress and mTOR signaling. Cell. 2008; 134: 451-60.

24. Rangarajan S, Bone NB, Zmijewska AA, Jiang S, Park DW, Bernard K,et al. Metformin reverses established lung fibrosis in a bleomycin model. Nat Med. 2018; 24: 1121-7.

25. Filderman AE, Genovese LA, Lazo JS. Alterations in pulmonary protective enzymes following systemic bleomycin treatment in mice. Biochem Pharmacol. 1988; 37: 1111-6.

26. Risha Y, Susevski V, Hüttmann N, Poolsup S, Minic Z, Berezovski MV. Breast cancer-derived microvesicles are the source of functional metabolic enzymes as potential targets for cancer therapy. Biomedicines. 2021; 9: 107.

\section{Figures}


a

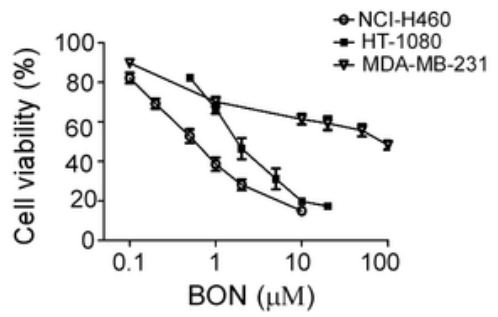

b

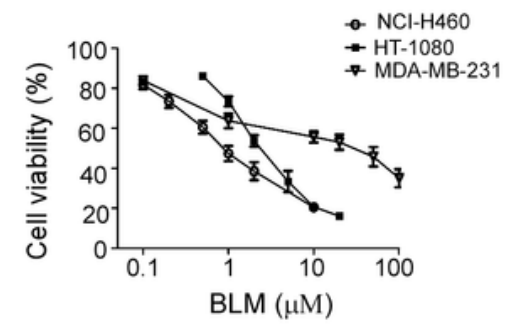

C

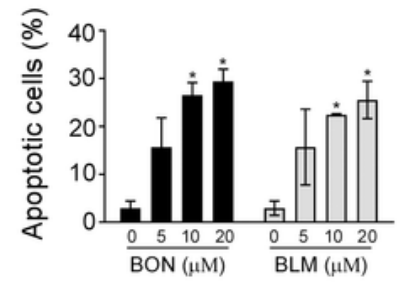

d

\begin{tabular}{llllll}
\multicolumn{5}{c}{$\operatorname{BON}(\mu \mathrm{M})$} \\
\hline 0 & 1 & 2 & 5 & 10 & 20
\end{tabular}

\begin{tabular}{llllll}
\multicolumn{5}{c}{$\operatorname{BLM}(\mu \mathrm{M})$} \\
\hline 0 & 1 & 2 & 5 & 10 & 20
\end{tabular}
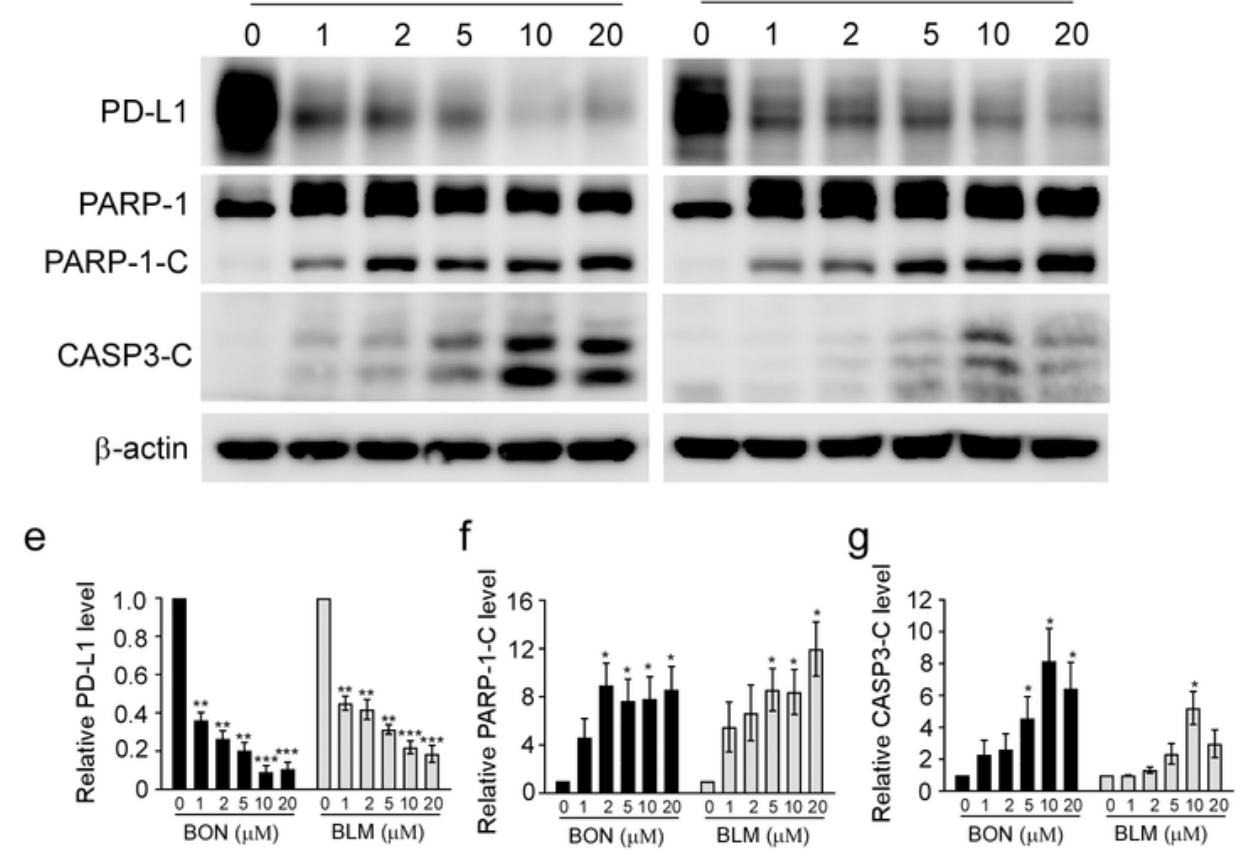

h

i

$\mathrm{k}$
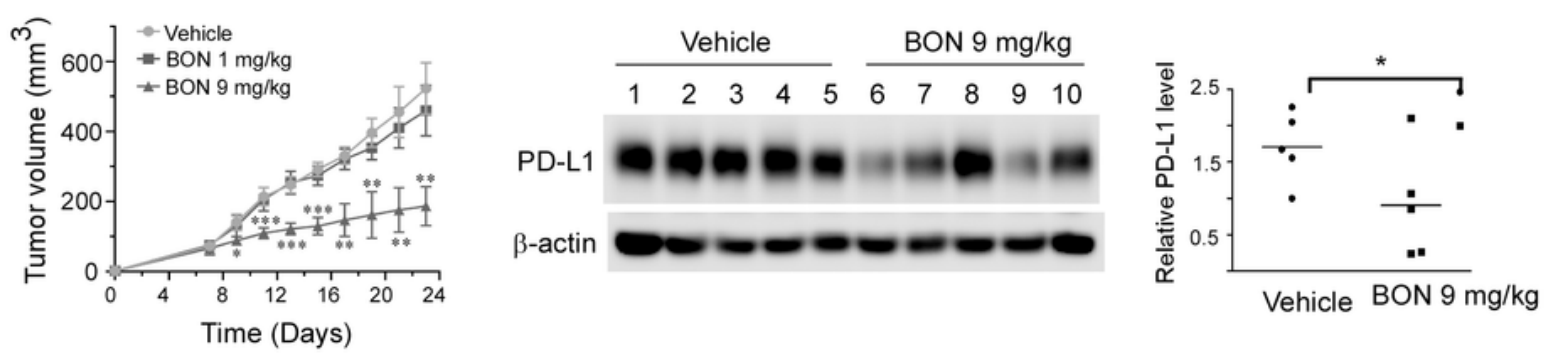

Fig. 1

\section{Figure 1}

BON-induced decrease in PD-L1 protein levels in vitro and in vivo. The cell survival rates were measured using CCK-8 assays after $72 \mathrm{~h}$ exposure to BON (a) and BLM (b). c The proportions of apoptotic cells were measured using flow cytometry. $(\mathrm{d}-\mathrm{g}) \mathrm{NCl}-\mathrm{H} 460$ cells were incubated with BON, BLM or DOX for $36 \mathrm{~h}$, and the protein levels of PD-L1, PARP-1, and cleaved caspase- 3 were detected by western blotting. (h) The volumes of tumor masses were determined in xenograft nude mice after drug administration. (i, $k$ ) The 
PD-L1 protein levels in tumor masses from the vehicle group and the BON $9 \mathrm{mg} / \mathrm{kg}$ group were determined. ${ }^{*} \mathrm{P}<0.05$, $* * \mathrm{P}<0.01$ and ${ }^{* *} \mathrm{P}<0.001$. ns, not statistically significant.

a
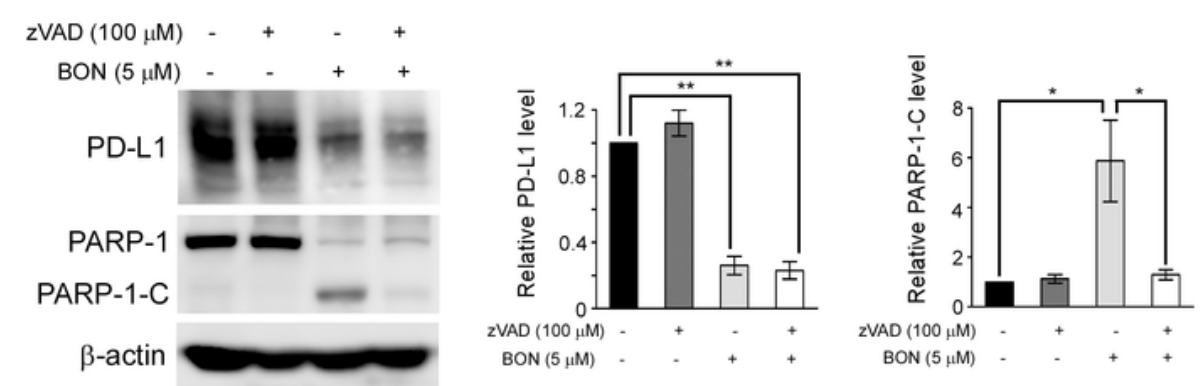

b
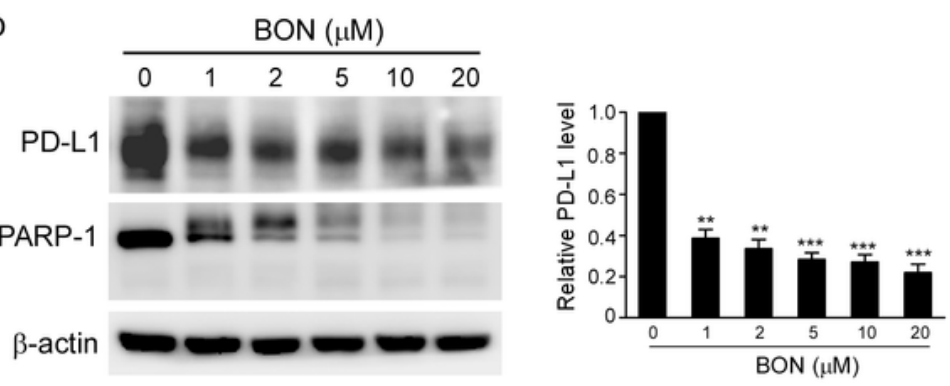

C
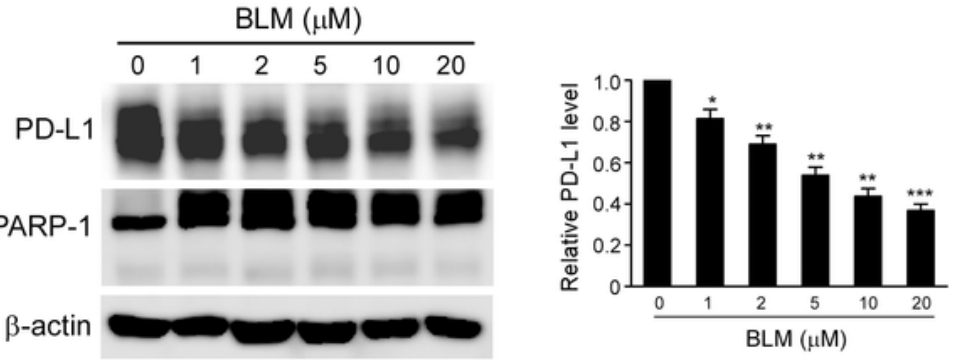

d
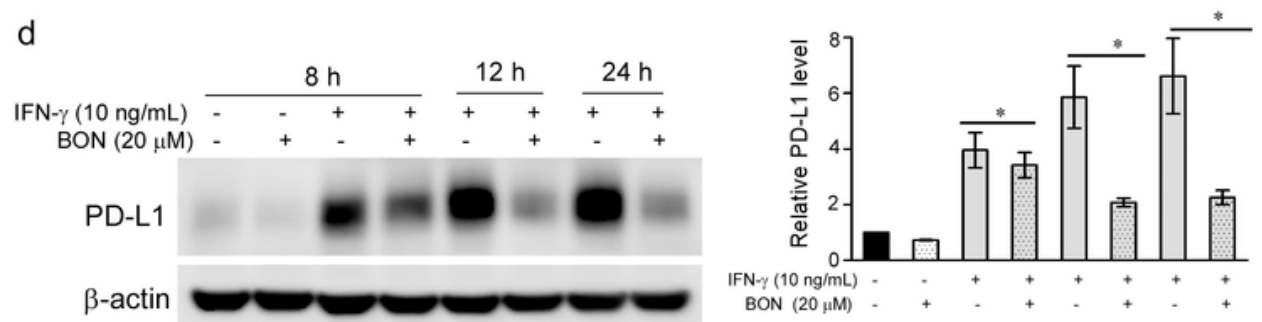

Fig. 2

\section{Figure 2}

Apoptosis-independent reduction of PD-L1 protein levels by BON. a NCl-H460 cells were pretreated with zVAD for $2 \mathrm{~h}$ and incubated with BON for $24 \mathrm{~h}$. The protein levels were then detected. $\mathrm{b}$ and $\mathrm{c}$ The protein levels were determined after exposure to BON or BLM for $8 \mathrm{~h}$. $\mathrm{d}$ After pretreatment with IFN-y for $6 \mathrm{~h}, \mathrm{~A} 549$ 
cells were exposed to BON for different period of time, and PD-L1 protein levels were determined. * $P<0.05$, ** $P<0.01$ and $* * * P<0.001$.

a

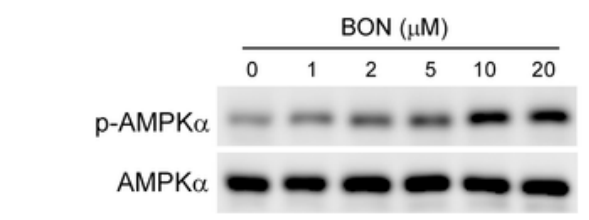

b
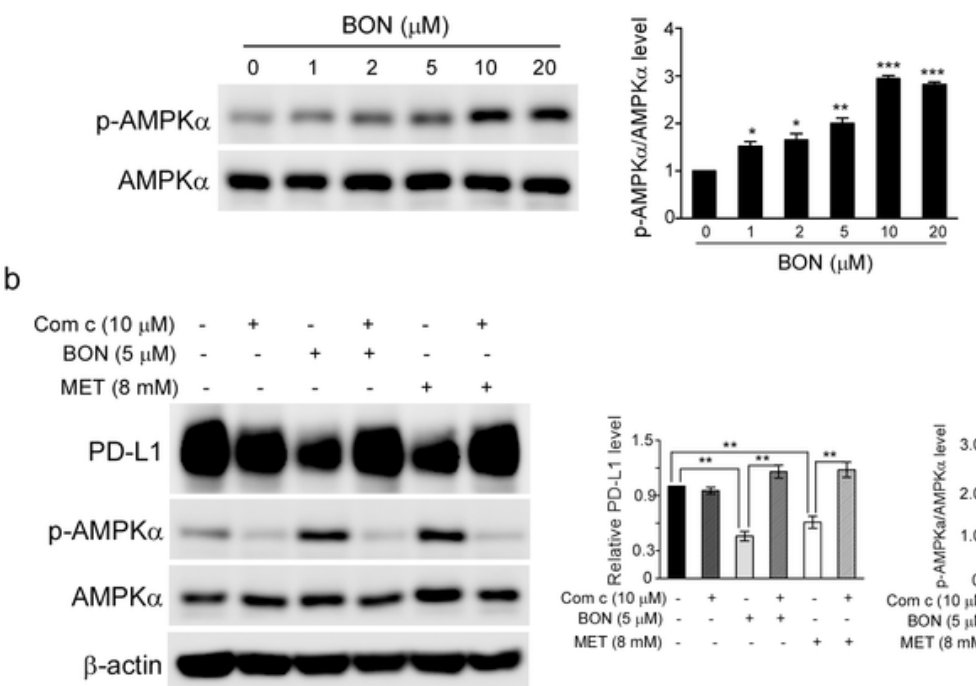

C

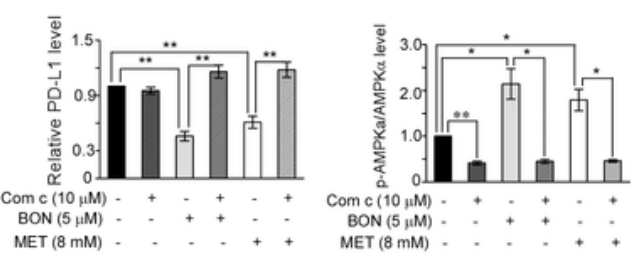

d
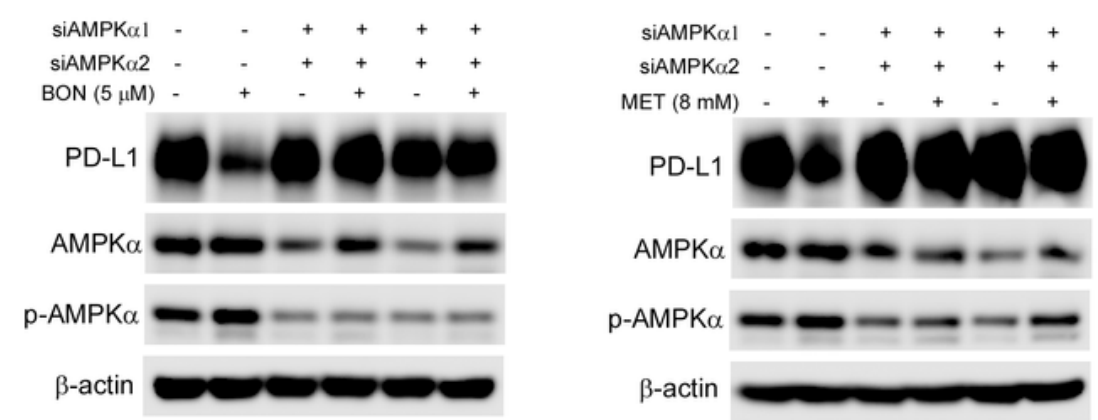

e
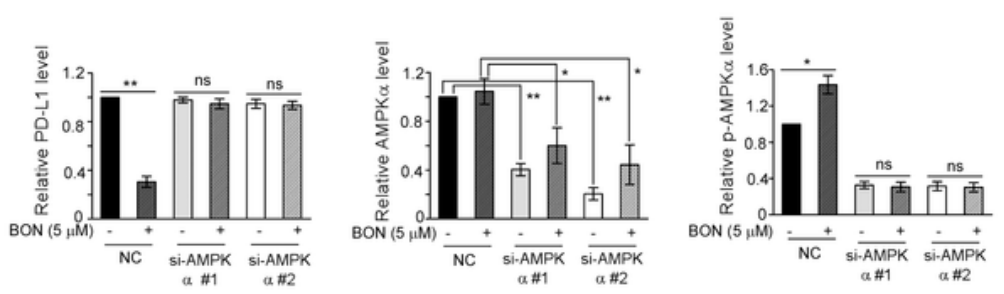

f
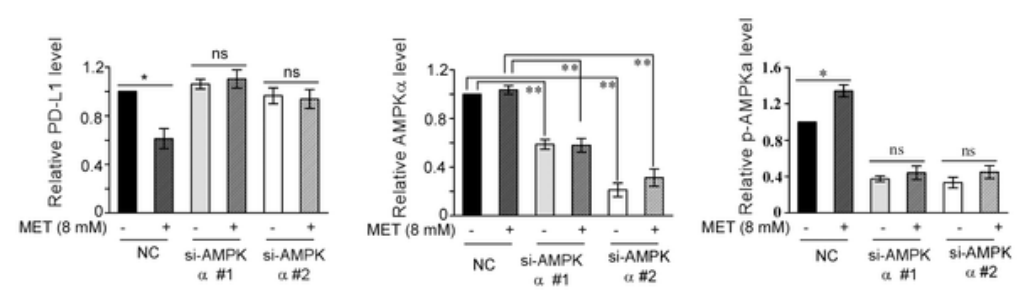

Fig. 3

\section{Figure 3}

The decrease of PD-L1 protein caused by BON treatment is required for AMPKa activation. a H460 cells were incubated with BON for $8 \mathrm{~h}$, and phosphorylation levels of AMPKa were then detected. $\mathrm{b}$ The cells were exposed to BON or MET for $8 \mathrm{~h}$ after a $2 \mathrm{~h}$ pretreatment of compound $\mathrm{c}$, and the protein levels were 
assessed. c and e The transfected cells were incubated with BON (c) or MET (e) for $8 \mathrm{~h}$ and the protein levels were detected. $d$ and $f$ The relative amounts of proteins from $(c, e)$ were quantified. ${ }^{*} P<0.05$, ** $P<0.01$ and NS, not statistically significant.

a
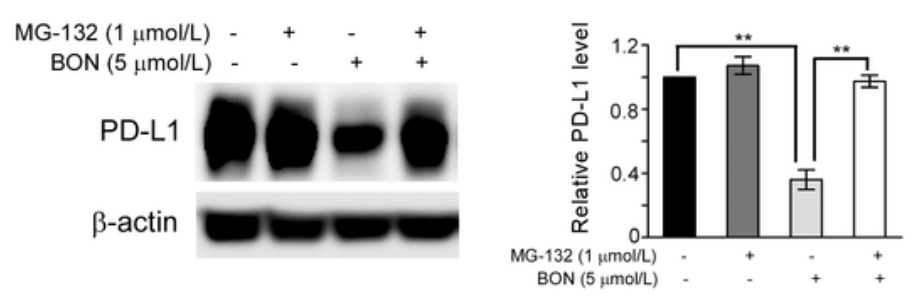

b

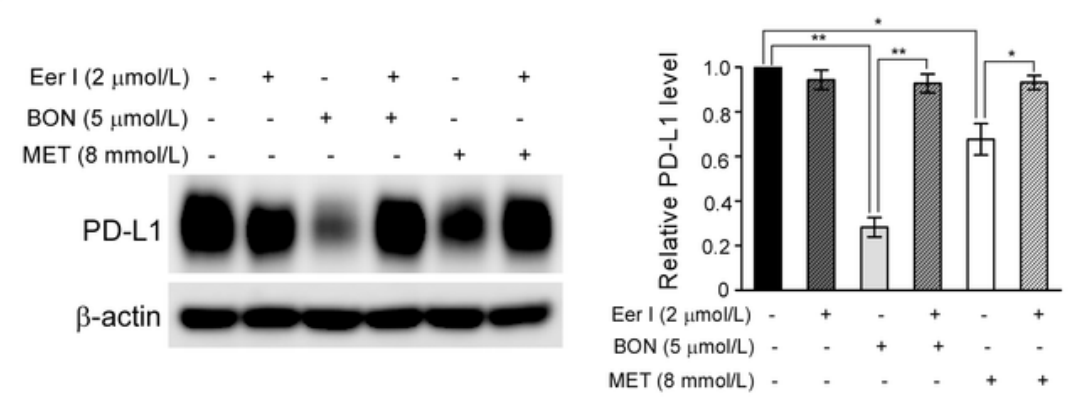

C
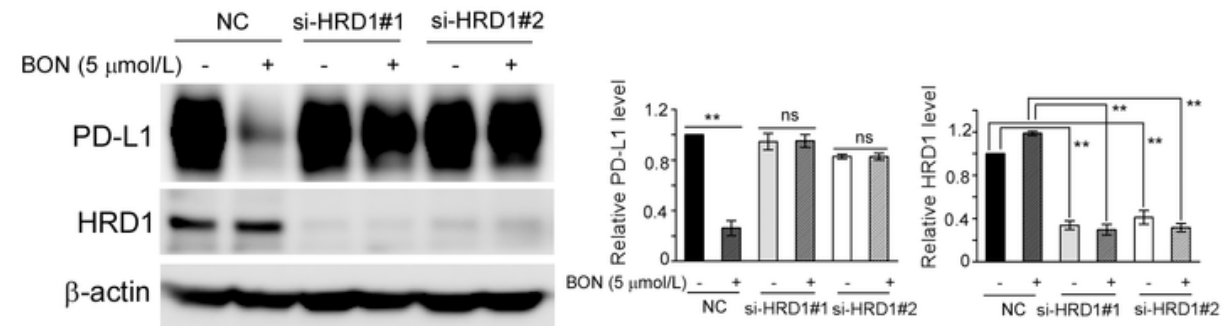

d

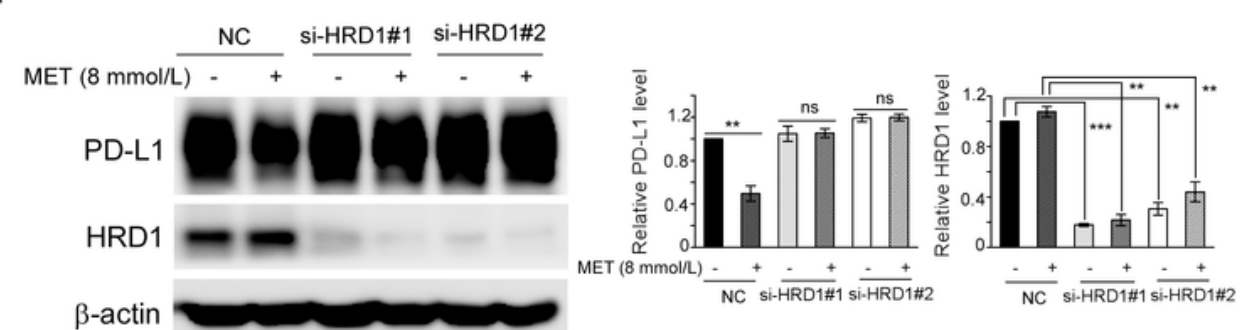

Fig 4

\section{Figure 4}

BON-induced decrease of PD-L1 protein levels is ERAD-dependent. a BON-induced decrease of PD-L1 protein levels was inhibited by MG-132, an inhibitor of proteasome degradation. b After pretreatment with 
eeyarestatin I for $2 \mathrm{~h}, \mathrm{NCl}-\mathrm{H} 460$ cells were exposed to $\mathrm{BON}$ for $8 \mathrm{~h}$, and the protein levels were measured. The transfected cells were incubated with BON (c) or MET (d) for $8 \mathrm{~h}$, and the protein levels were detected. * $P<0.05$, ** $P<0.01$ and NS, not statistically significant.

\section{Supplementary Files}

This is a list of supplementary files associated with this preprint. Click to download.

- sup1.pdf

- sup2.pdf 